Секция 10. Фотонные кристаллы, микрорезонаторы и метаматериалы. Нанофотоника

\title{
Сравнительный анализ люминесценции слоев n-Ge, выращенных на Ge(001) и Si(001) подложках
}

\author{
Новиков А.В., Юрасов Д.В., Байдакова Н.А., Бушуйкин П.А., Андреев Б.А., Алешкин В.Я., \\ Юнин П.А., Яблонский А.Н., Красильник З.Ф.
}

ИФМ РАН, 603950, Нижний Новгород, Россия

DOI 10.34077/Semicond2019-409

Легированные донорами слои $\mathrm{Ge}$, сформированные на $\mathrm{Si}$, являются перспективным материалом кремниевой оптоэлектроники и плазмоники. Это связано с тем, что легирование донорами за счет роста заселенности электронных состояний в Г-долине позволяет увеличить эффективность излучательной рекомбинации носителей заряда в Ge. При этом установлено существенное различие спектров фотолюминесценции (ФЛ) эпитаксиальных n-Ge/ $\mathrm{Si}(001)$ структур и объемного $\mathrm{Ge}$, которое связывается с различными причинами [1]. Однако сравнение ФЛ n-Ge/Si слоев с ФЛ объемного Ge представляется не корректным из-за различий в толщинах, условий формирования и уровней их легирования. В настоящей работе для установления влияния на излучательные свойства слоев $\mathrm{n}-\mathrm{Ge}$ концентрации доноров, упругих напряжений и дефектов впервые выполнены сравнительные исследования ФЛ легированных сурьмой слоев n-Ge, выращенных на $\mathrm{Si}(001)$ и $\mathrm{Ge}(001)$ подложках.

Слои $\mathrm{Ge}$, легированные $\mathrm{Sb}$, были выращены методом МПЭ. При росте гомоэпитаксиальных структур на $\mathrm{Ge}(001)$ подложках осаждение слоев $\mathrm{Ge}: \mathrm{Sb}$ проводилось на тонком Ge буфере. В случае роста на $\mathrm{Si}(001)$ формирование слоев $\mathrm{Ge}: \mathrm{Sb}$ было выполнено на 500 нм релаксированном Ge буфере с плотностью прорастающих дефектов $\sim 5^{*} 10^{7} \mathrm{~cm}^{-2}$ [2]. По данным ВИМС содержание $\mathrm{Sb}$ в слоях $\mathrm{Ge}: \mathrm{Sb}$, выращенных на различных подложках, варьировалось от $\mathrm{N}_{\mathrm{Sb}} \sim 10^{18} \mathrm{~cm}^{-3}$ до $2 * 10^{20} \mathrm{~cm}^{-3}$. Концентрация электронов, определенная из транспортных измерений, рентгенодифракционного анализа и спектров отражения [2] показала полную электрическую активацию примеси до $\mathrm{N}_{\mathrm{Sb}}=$ (7$8)^{*} 10^{19} \mathrm{~cm}^{-3}$ и ее падение до $50 \%$ для $\mathrm{N}_{\mathrm{Sb}} \sim 2 * 10^{20} \mathrm{~cm}^{-3}$. Люминесцентные исследования, выполненные при комнатной температуре, показали, что при всех исследованных $\mathrm{N}_{\mathrm{Sb}}$ в сигнал ФЛ слоев $\mathrm{Ge}: \mathrm{Sb} / \mathrm{Ge}(001)$, в отличие от слоев $\mathrm{Ge}: \mathrm{Sb} / \mathrm{Si}(001)$, значительный вклад дают непрямые оптические переходы (рис. 1). Данный факт связывается с большим временем жизни носителей заряда в гомоэпитаксиальных структурах $\mathrm{Ge}: \mathrm{Sb} / \mathrm{Ge}$ вследствие отсутствия в них дефектов кристаллической решетки, связанных с релаксацией упругих напряжений. Установлено, что значительное возрастание вклада прямых оптических переходов в общий сигнал ФЛ слоев $\mathrm{Ge}: \mathrm{Sb} / \mathrm{Ge}(001)$, наблюдаемое при увеличении $\mathrm{N}_{\mathrm{Sb}}$, вызвано ростом заселенности электронных состояний в Г-долине. Выявлено, что значительное влияние на излучательные свойства $\mathrm{Ge}: \mathrm{Sb}$ слоев с частичной электрической активацией примеси, выращенных на различных подложках, оказывают центры безызлучательной рекомбинации, которыми могут являться кластеры примесных атомов. Расчеты зонной диаграммы Ge:Sb структур и моделирование их спектров ФЛ

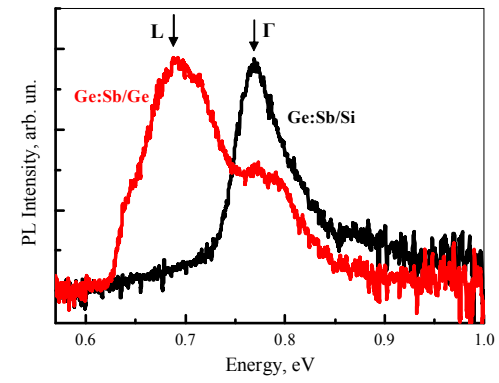

Pис.1. - Спектры ФЛ Ge:Sb слоев с $\quad N S b \sim 2 * 10^{19} \quad \mathrm{~cm}^{-3}$, выраменных на $\mathrm{Si}$ и $\mathrm{Ge}$ подложках. позволили выявить количественные изменения ширин прямой и непрямой запрещенных зон в $\mathrm{Ge}$, вызванные эффектом их перенормировки при легировании.

Работа выполнена при финансовой поддержке РФФИ (гранты № 16-29-14056 и №18-02-00771).

[1] G. Grzybowski et al., Phys. Rev. B 84, 205307 (2011).

[2] D.V. Yurasov et al., J. Crystal Growth 491, 26 (2018). 